\title{
'Luoxue No. 1', A Dual-use Radish (Raphanus sativus L.) with Edible Roots and Greens
}

\author{
Shisheng $\mathbf{L i}^{1}$ \\ Collaborative Innovation Center for the Characteristic Resources \\ Exploitation of Dabie Mountains, Key Laboratories of Economic Forest \\ Germplasm Improvement and Comprehensive Resources Utilization of Hubei \\ Province, College of Life Science, Huanggang Normal University, \\ Huanggang, Hubei 438000, China
}

\section{Qiufang Xiong ${ }^{1}$}

Institute of Vegetable, Wuhan Academy of Agricultural Sciences, Wuhan 430345, China

\section{Jingcai Li, Yuanping Fang, and Jun Xiang ${ }^{2}$ \\ Collaborative Innovation Center for the Characteristic Resources Exploitation of Dabie Mountains, Key Laboratories of Economic Forest Germplasm Improvement and Comprehensive Resources Utilization of Hubei Province, College of Life Science, Huanggang Normal University, Huanggang, Hubei 438000, China}

Additional index words. biological character, cultivar, mutant, potherb mustard

Radish (Raphanus sativus L., $2 n=18$ ) has tuberous roots and is consumed globally. Breeders have developed different types of radish, including oil radish, silique radish, and leafy radish. Radish is a particularly important vegetable crop in East Asia. In China, radish has the second highest acreage among vegetable crops. The nutritional quality of radish is particularly appealing to consumers. In terms of morphology and color, several types of radish roots are available to consumers (Gutiérrez and Perez, 2004). There are also several ways to process radish roots. They can be eaten raw or cooked, and preserved by pickling, canning, or drying.

Radish is not only a vegetable crop but also an important source of medicinal compounds for diseases such as gall bladder trouble, diabetes, hepatitis, and gastrointestinal disorders (Chaturvedi, 2008). The juice from radish roots has antimicrobial activity against Bacillus subtilis, Pseudomonas aeruginosa, and Salmonella typhosa (Abdou et al., 1972). More importantly, sulforaphane, which is found in radish, has anticancer properties (Baek et al., 2008; Beevi et al., 2010; Kim et al., 2014). In addition, anthocyanin pigments, which are found in radish, have strong antioxidant activity that benefits

Received for publication 12 Mar. 2018. Accepted for publication 26 Apr. 2018.

This work was supported by Hubei Special Project for Development of Science and Technology in Local by Central Guidance (2018ZYYD019).

${ }^{1}$ These authors contributed equally to this work. ${ }^{2}$ Corresponding author. E-mail: swxj@hgnu.edu. cn human health (Lim et al., 2016; Park et al., 2011). Radish is not only a multifunctional crop but also an ideal model crop.

To improve radish breeding, in-depth molecular breeding studies of radish have been conducted. During the past few years, large-scale radish genomic and genetic information has accumulated, and several radish databases have been constructed (Shen et al., 2013). More importantly, the genome of radish was sequenced by Kitashiba et al. (2014). A genetic linkage map and quantitative trait loci map of cadmium accumulation in radish were made ( $\mathrm{Xu}$ et al., 2012). These are useful for selecting excellent radishes with high cadmium accumulation. Transcriptome analysis of the radish roots was performed, and EST-SSR markers for radish were developed (Wang et al., 2012). Although new markers and genes were isolated from radish to be used for radish breeding, new radish cultivars with high yield and quality were still difficult to obtain.

Potherb mustard (Brassica juncea var. crispifolia auct. non L. H. Bailey, $2 n=36$ ) is consumed as a leafy vegetable and sold as a pickled vegetable with special flavor and umami ( $\mathrm{Li}$ et al., 2012). Many functional molecules, such as amino acids, glucosinolates, and other secondary metabolites, have been found in potherb mustard (Dai et al., 2011). Potherb mustard is grown throughout China and only the aboveground part is consumed.

In this study, we analyzed a new type of radish that can be consumed as a root and leafy vegetable (Zhang et al., 2012). The new radish was required to have improved above- and underground characteristics, and it resulted from hybridization between root radish (R. sativus L. var. longipinnatus L. H. Bailey) and related or distantly cultivated crops, which could provide improved germplasm for breeding programs. A new radish cultivar was selected from the cross between the abovementioned root radish and potherb mustard (B. juncea var. crispifolia auct. non L. H. Bailey), which differed from the parents as the entire plant is edible. The new cultivar is called a dual-use radish, as the aboveground part resembles potherb mustard and the underground part resembles radish. Both the leaves and roots are edible. In addition, in terms of quantity and quality, the leaves and tuberous roots of this dual-use radish are superior to those of potherb mustard and radish. Our experimental evidence has indicated that the dual-use radish has the same number of chromosomes as radish, with some of the same SSR markers as radish, but no SSR markers in common with potherb mustard.

\section{Origin}

The F1 hybrid was produced in 2006 by crossing the radish cultivar Wuqing (a radish cultivar with normal cracks on the leaf margin and a green part above the tuberous root that was cultured in Wuhan) with potherb mustard. A new radish with mutated leaf phenotypes was identified from selfcrossing offspring of the F1 progeny. 'Wuqing' and potherb mustard were used as parental cultivars, and root weight, leaf morphology, and root and leaf yield of the parental cultivars and hybrid were recorded and evaluated in an experimental field at Institute of Vegetable, Wuhan Academy of Agricultural Sciences (lat. $114^{\circ} 27^{\prime} 51.40^{\prime \prime} \mathrm{N}$, long. $30^{\circ} 42^{\prime} 20.35^{\prime \prime} \mathrm{E}$ ). We selected stable inbred lines with obvious mutated leaves until the F5 generation, which was created by self-pollinating for four generations (Supplemental Fig. 1). The aboveground characteristics of the F5 lines ('Luojie No. 4') resembled potherb mustard, and the underground characteristics resembled radish. To improve the field product, the F5 line ('Luojie No. 4') was crossed with the 'Wuqing' male sterile line in 2011; offspring of this cross, which have traits from both 'Wuqing' and potherb mustard, were deemed a dual-use radish. Comparative trials and morphological and cytological experiments were conducted at the end of 2011, and this new dual-use radish was named 'Luoxue No. 1' based on its excellent performance (average temperature $14.06{ }^{\circ} \mathrm{C}$, maximum temperature $33{ }^{\circ} \mathrm{C}$ from August to November in Wuhan). The aboveground part of 'Luoxue No. 1' resembled that of potherb mustard (Fig. 1A), which improved the ventilation, light transmittance, and light energy utilization of the plant and inhibited the occurrence of pests and diseases to an extent; 'Luoxue No. 1' also has tuberous roots that resembled those of the 'Wuqing' radish (Fig. 1B). 


\section{Description and Performance}

The resulting hybrid was planted in Hannan, Huangpi, and Xinzhou districts, Wuhan, China. The above- and underground parts of 'Wuqing' radish, 'Luoxue No. 1', and potherb mustard were measured. The distribution of cracks on the leaves of 'Luoxue No. 1' resembled that of potherb mustard and differed from that of 'Wuqing' (Fig. 2A-C), whereas the root of 'Luoxue No. 1 ' was a tuberous root like that of 'Wuqing' radish (Fig. 2D). Data were collected on the yield of leaves and roots, and hollows in the root, throughout the growing season. The root and leaf yields of the hybrid surpassed those of 'Wuqing' (Table 1). The leaf yield of 'Luoxue No. 1' was 60,055 kg.ha- ${ }^{-1}$ after $79 \mathrm{~d}$, which was greater than that of 'Wuqing' $\left(51,565 \mathrm{~kg} \cdot \mathrm{ha}^{-1}\right)$. The tuberous root yield of 'Luoxue No. 1' was $68,865 \mathrm{~kg} \cdot \mathrm{ha}^{-1}$ at $79 \mathrm{~d}$, also higher than that of 'Wuqing' $(60,905$ $\mathrm{kg} \cdot \mathrm{ha}^{-1}$ ). Both the above- and underground parts of the new cultivar were superior to those of 'Wuqing'. More importantly, the proportion of hollows in 'Luoxue No. 1' was $0 \%$, which is less than that in 'Wuqing'. As a result, the new cultivar was identified as a dual-use radish.

Additional testing was performed on the dual-use radish and 'Wuqing'. The amino acid contents of the leaves of 'Wuqing', the dual-use radish, and Potherb mustard were analyzed using high-performance liquid chromatography. Content of glycine, which contributes to flavor, was substantially higher in the dual-use radish $(9.14 \%, P<$ $0.01)$ compared with the potherb mustard and 'Wuqing' radish (Table 2). There were no significant differences in other amino acids, such as Ser, Glu, and Ala (Table 2). Dual-use radish aboveground and underground production, in terms of quantity and quality, were superior to potherb mustard and 'Wuqing' radish.

Leaf trichome densities differed among dual-use radish, 'Wuqing' radish, and potherb mustard. 'Wuqing' radish had very dense leaf trichomes, which function in secretion and defense against invaders. As the density of trichomes increases, the quality, in terms of texture, declines. The most popular radish varieties have less dense leaf trichomes. The density of leaf trichomes in the dual-use radish was lower than that of 'Wuqing' radish, but higher than that of potherb mustard (Supplemental Fig. 2C). Overall, the leaf of dual-use radish was similar to that of potherb mustard.

The continued development process of roots in dual-use radish, potherb mustard, and 'Wuqing' radish was elucidated (Supplemental Fig. 2D). At maturity, the tuberous roots of the dual-use radish were larger than those of potherb mustard and smaller than the 'Wuqing' radish roots (Supplemental Fig. 2D and C). Despite the smaller tuberous root of the dual-use radish compared with 'Wuqing', the hollowness ratio in the dual-use radish was lower and overall tuberous root yield was higher.

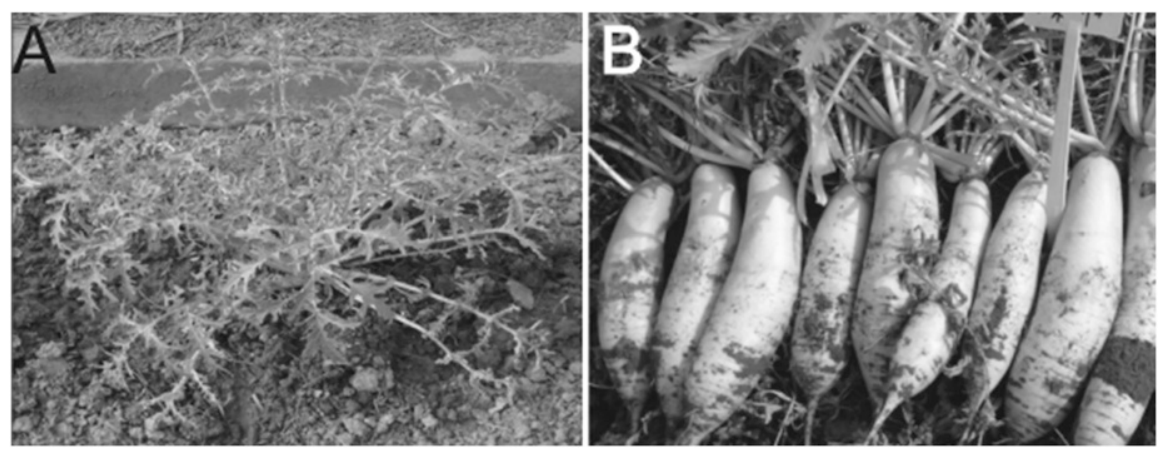

Fig. 1. Aboveground (A) and underground (B) parts of the dual-use radish vegetable organs.
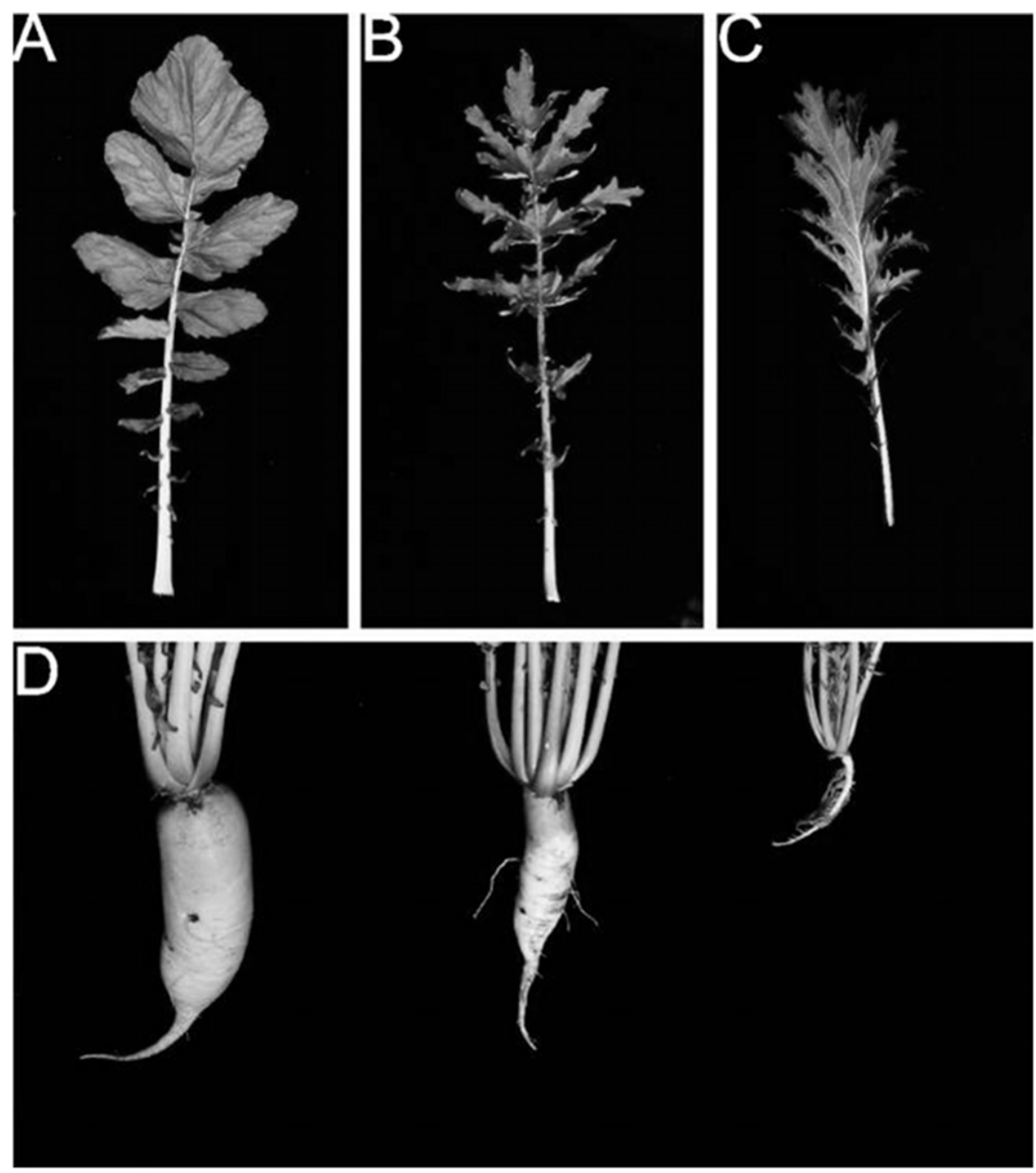

Fig. 2. Comparisons of the morphology of mature roots and leaves of 'Wuqing' radish, dual-use radish, and potherb mustard. Mature leaf from (A) 'Wuqing' radish, (B) dual-use radish, and (C) potherb mustard. (D) Comparison of the mature roots of 'Wuqing' radish (left), dual-use radish (middle), and potherb mustard (right).

\section{Chromosome and SSR Analysis}

Results from karyotype analysis indicated that the dual-use radish has 18 chromosomes, as does the radish (Fig. 3B). The number of chromosomes can determine the species attributes. Based on the number of chromosomes (Fig. 3), the dual-use radish is still a radish.

Recognizing the differences between the dual-use and 'Wuqing' radishes, we attempted to determine their relatedness in terms of molecular markers. Forty SSR markers were selected for our study (Flannery et al., 2006). Primer sequences are presented in Supplemental Table 1. Only two SSR markers, M7 and P28, exhibited bands unique to dual-use radish and 'Wuqing' radish compared with potherb mustard. The bands amplified with each dualuse radish SSR marker were identical to the 'Wuqing' radish bands, whereas there were no 
bands in common with potherb mustard (Fig. 4). Our data do not prove that dual-use radish has DNA fragments that originated from potherb mustard, which might be because of the relatively low number of SSR markers. Based on the karyotype analysis, we speculate that, in the hybridization process, dual-use radish may have received alien DNA fragments from a species other than radish,

which may have resulted in the mutated leaf of the dual-use radish. Some recent studies reported that a transgenic radish was obtained using a floral-dip method (Curtis, 2011; Curtis et al., 2002; Yu et al., 2016). Curtis et al. (2002) reported a transgenic radish with delayed bolting and flowering that resulted from it expressing an antisense GIGANTEA (GI) gene fragment in radish. Yu et al. (2016)

Table 1. Comparison of the tuberous roots, leaves, and the proportion of hollow area in the root of dual-use and 'Wuqing' radish.

\begin{tabular}{lcccc}
\hline & & Wuqing radish & Dual-use radish & Potherb mustard \\
\hline & $69-\mathrm{d}$ & $49,265 \pm 627.99^{*}$ & $53,395 \pm 493.28^{*}$ & - \\
Tuberous root yield & $79-\mathrm{d}$ & $60,905 \pm 537.52^{*}$ & $68,865 \pm 546.43^{*}$ & - \\
$\left(\mathrm{kg} \cdot \mathrm{ha}^{-1}\right.$, mean $\left.\pm \mathrm{SE}\right)$ & $89-\mathrm{d}$ & $75,395 \pm 523.74^{*}$ & $84,355 \pm 348.17^{*}$ & - \\
& $69-\mathrm{d}$ & $34,930 \pm 525.81^{*}$ & $42,290 \pm 392.91^{*}$ & - \\
Leaf yield & $79-\mathrm{d}$ & $51,565 \pm 584.32^{*}$ & $60,055 \pm 384.32^{*}$ & - \\
$\left(\mathrm{kg} \cdot \mathrm{ha}^{-1}\right.$, mean $\left.\pm \mathrm{SE}\right)$ & $89-\mathrm{d}$ & $39,900 \pm 514.47^{*}$ & $39,950 \pm 538.08^{*}$ & $69,600 \pm 815.58^{*}$ \\
& $69-\mathrm{d}$ & $0.054 \pm 0.006^{* *}$ & $0^{* *}$ & - \\
Ratio of hollowness & $79-\mathrm{d}$ & $0.152 \pm 0.009^{* *}$ & $0^{* *}$ & - \\
$(\%$, mean $\pm \mathrm{SE})$ & $89-\mathrm{d}$ & $0.533 \pm 0.040^{* *}$ & $0^{* *}$ & - \\
\hline
\end{tabular}

*Significant at the 0.05 level; ${ }^{* *}$ significant at the 0.01 level.

Table 2. Comparision of the ratio of flavor amino acids to all amino acids among 'Wuqing' radish, dual-use radish, and mustard.

\begin{tabular}{lccc}
\hline Amino acid & $\begin{array}{c}\text { Wuqing radish } \\
(\%, \text { mean } \pm \mathrm{SE})\end{array}$ & $\begin{array}{c}\text { Dual-use radish } \\
(\%, \text { mean } \pm \mathrm{SE})\end{array}$ & $\begin{array}{c}\text { Potherb mustard } \\
(\%, \text { mean } \pm \mathrm{SE})\end{array}$ \\
\hline Asp & $16.47 \pm 1.14^{*}$ & $12.09 \pm 1.40^{*}$ & $27.04 \pm 1.17^{*}$ \\
Thr & $4.51 \pm 0.09^{* *}$ & $3.82 \pm 0.08^{* *}$ & $2.72 \pm 0.08^{* *}$ \\
Ser & $6.57 \pm 0.45^{*}$ & $6.22 \pm 0.48^{*}$ & $8.19 \pm 0.60^{*}$ \\
Glu & $52.54 \pm 1.93^{* *}$ & $25.39 \pm 1.00^{* *}$ & $25.33 \pm 1.10^{* *}$ \\
Ala & $4.77 \pm 0.29^{*}$ & $4.75 \pm 0.80^{*}$ & $5.25 \pm 0.67^{*}$ \\
Gly & $0.26 \pm 0.02^{* *}$ & $9.14 \pm 0.86^{* *}$ & $0.27 \pm 0.03^{* *}$ \\
\hline
\end{tabular}

*Significant at the 0.05 level; **significant at the 0.01 level.
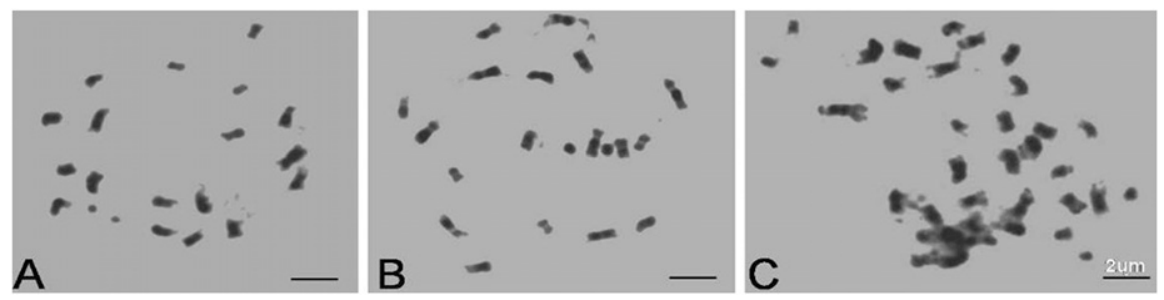

Fig. 3. Karyotypes of 'Wuqing' radish $(\mathbf{A}, 2 n=18)$, dual-use radish $(\mathbf{B}, 2 n=18)$, and potherb mustard $(\mathbf{C}, 2 n=36)$.

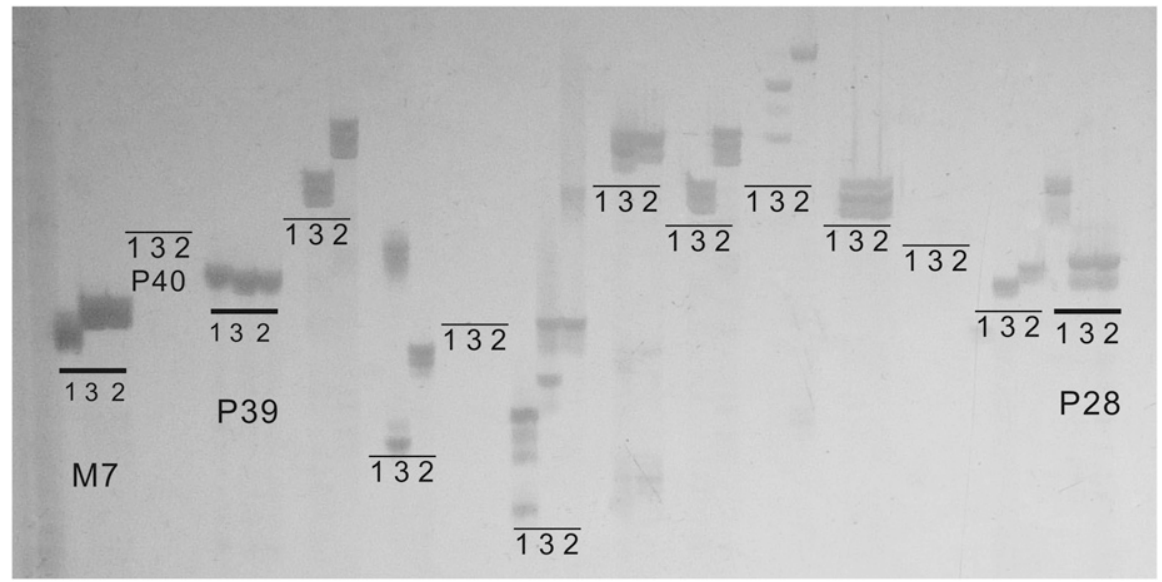

Fig. 4. Amplification of the simple sequence repeat markers of 'Wuqing' radish (left lane), dual-use radish (middle lane), and potherb mustard (right lane). introduced a green fluorescence protein into radish and observed green fluorescence in the root of white radish. Introducing foreign DNA fragments into radish can profoundly modify the physiological traits of radish and can be used to improve the breeding process.

\section{Uses}

A new kind of root and leafy vegetable was selected and named 'Luoxue No. 1'. It can grow in the Changjiang River Basin and is adapted to that climate. The period of growth of 'Luoxue No. 1' is $\approx 90-120 \mathrm{~d}$ when it is sown at the end of August using 7.5-12 $\mathrm{kg}$ of seeds per hectare.

\section{Availability}

'Luoxue No. 1' was transferred to Wuhan Seven Leaf Red Urban Horticulture Co., Ltd. (Wuhan, China) for commercial production and sale. A limited quantity of seed may be made available for research purposes only by sending a request to the first author (21581872@qq.com or6511311@qq.com).

\section{Literature Cited}

Abdou, I.A., A.A. Abou-Zeid, M.R. El-Sherbeeny, and Z.H. Abou-El-Gheat. 1972. Antimicrobial activities of Allium sativum, Allium cepa, Raphanus sativus, Capsicum frutescens, Eruca sativa, Allium kurrat on bacteria. Qual. Plant. Mater. Veg. 22:29-35.

Baek, S.H., M. Park, J.H. Suh, and H.S. Choi. 2008. Protective effects of an extract of young radish (Raphanus sativus L.) cultivated with sulfur (sulfur-radish extract) and of sulforaphane on carbon tetrachloride-induced hepatotoxicity. Biosci. Biotechnol. Biochem. 72(5):1176-1182.

Beevi, S.S., L.N. Mangamoori, M. Subathra, and J.R. Edula. 2010. Hexane extract of Raphanus sativus L. roots inhibits cell proliferation and induces apoptosis in human cancer cells by modulating genes related to apoptotic pathway. Plant Foods Hum. Nutr. 65(3):200-209.

Chaturvedi, P. 2008. Inhibitory response of Raphanus sativuson lipid peroxidation in albino rats. Evid. Based Complement. Alternat. Med. 5:55-59.

Curtis, I.S. 2011. Genetic engineering of radish: Current achievements and future goals. Plant Cell Rpt. 30(5):733.

Curtis, I.S., H.G. Nam, J.Y. Yun, and K.H. Seo. 2002. Expression of an antisense GIGANTEA (GI) gene fragment in transgenic radish causes delayed bolting and flowering. Transgenic Res. 11(3):249-256

Dai, F.G., Z. Hu, G.P. Chen, B.Q. Wang, and S. Zhou. 2011. A simple method to obtain transgenic mustard. Life Sci. Res. 15(1):019-023.

Flannery, M.L., F.J. Mitchell, S. Coyne, T.A Kavanagh, J.I. Burke, N. Salamin, P. Dowding, and T.R. Hodkinson. 2006. Plastid genome characterization in Brassica and Brassicaceae using a new set of nine SSRs. Theor. Appl. Genet. 113(7):1221-1231.

Gutiérrez, R.M. and R.L. Perez. 2004. Raphanus sativus (Radish): Their chemistry and biology. Sci. World J. 4:811

Kim, K.H., E. Moon, S.Y. Kim, S.U. Choi, J.H. Lee, and K.R. Lee. 2014. 4-Methylthio-butanyl derivatives from the seeds of Raphanus sativus and their biological evaluation on 
anti-inflammatory and antitumor activities. J. Ethnopharmacol. 151(1):503-508.

Kitashiba, H., F. Li, H. Hirakawa, T. Kawanabe, Z. Zou, Y. Hasegawa, K. Tonosaki, S. Shirasawa, A. Fukushima, S. Yokoi, Y. Takahata, T. Kakizaki, M. Ishida, S. Okamoto, K. Sakamoto, K. Shirasawa, S. Tabata, and T. Nishio. 2014. Draft sequences of the radish (Raphanus sativus L.) genome. DNA Res. 21(5):481-90.

Li, R., J.J. Wang, Z. Zhang, F. Shen, G. Zhang, R. Qin, X. Li, and R. Xiao. 2012. Nutrient transformations during composting of pig manure with bentonite. Bioresour Technol. 121:362-368.

Lim, S.H., J.H. Song, D.H. Kim, J.K. Kim, J.Y. Lee, Y.M. Kim, and S.H. Ha. 2016. Activation of anthocyanin biosynthesis by expression of the radish R2R3-MYB transcription factor gene RsMYB1. Plant Cell Rpt. 35(3):641-653.

Park, N.I., H. Xu, X. Li, I.H. Jang, S. Park, G.H. Ahn, Y.P. Lim, S.J. Sun Ju Kim, and S.U. Park. 2011. Anthocyanin accumulation and expression of anthocyanin biosynthetic genes in radish (Raphanus sativus). J. Agr. Food Chem. 59:6034-6039.

Shen, D, H. Sun, M. Huang, Y. Zheng, X. Li, and Z. Fei. 2013. Radish base: A database for genomics and genetics of radish. Plant Cell Physiol. 54(2): e3.

Wang, S., X. Wang, Q. He, X. Liu, W. Xu, L. Li, J. Gao, and F. Wang. 2012. Transcriptome analysis of the roots at early and late seedling stages using illumina paired-end sequencing and de- velopment of EST-SSR markers in radish. Plant Cell Rpt. 31(8):1437-1447.

$\mathrm{Xu}$, L., L. Wang, Y. Gong, W. Dai, Y. Wang, X. Zhu, T. Wen, and L. Liu. 2012. Genetic linkage map construction and QTL mapping of cadmium accumulation in radish (Raphanus sativus L.). Theor. Appl. Genet. 125(4):659-670.

Yu, X.M., L. Wu, K. Wang, S.S. Li, and M. Xu. 2016. A primary study on genetic transformation in radish by Agrobacterium tumefaciens. North. Hort. 2016(6):99-102.

Zhang, XK, Q.F. Xiong, S.S. Li, X.Q. Zhang, and G.S. Zhang. 2012. Study on a new hybrid breeding between Raphanus sativus and Brassica juncea by distant hybridization. Acta Agr. Jiangxi. 24(11):1-4. 


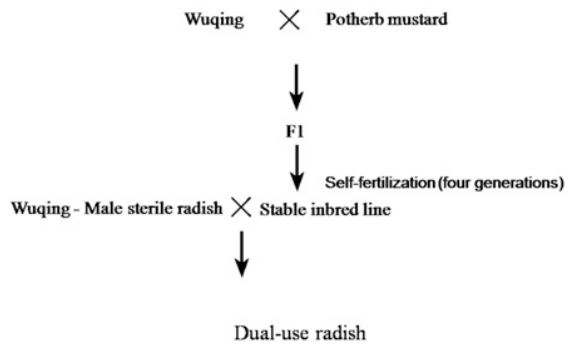

Supplemental Fig. 1. Flow chart of the selection process for the dual-use radish.
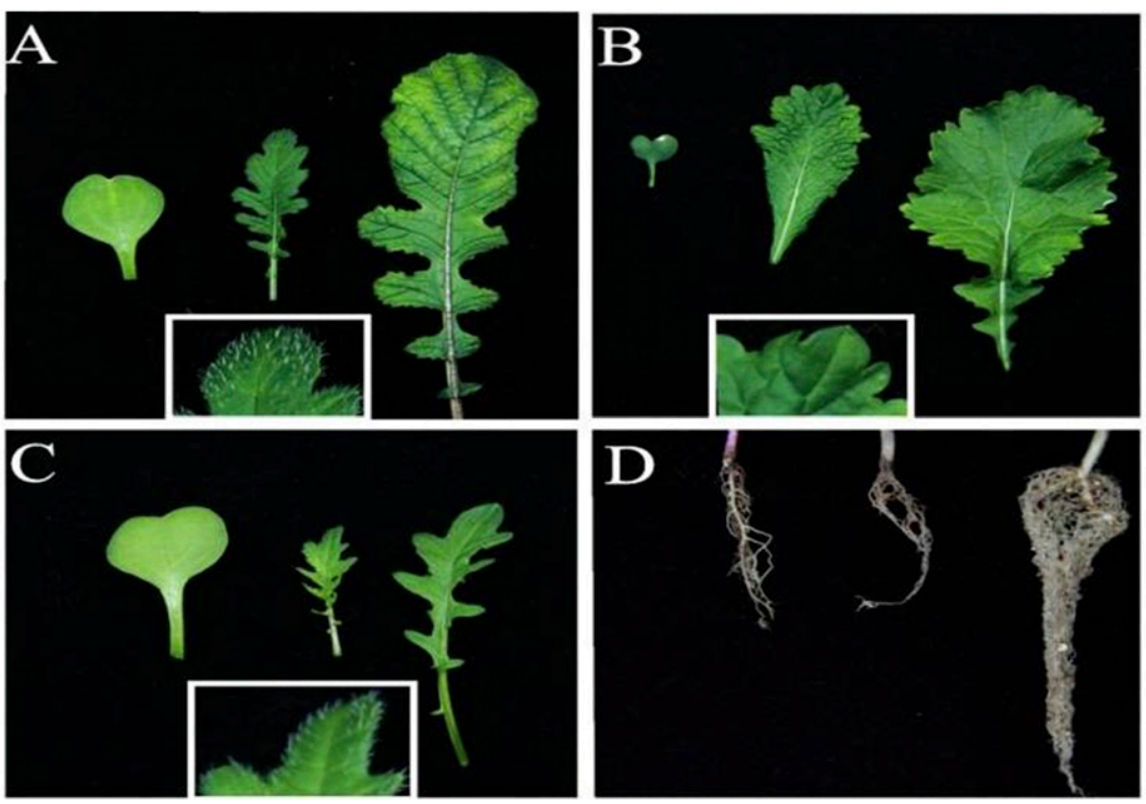

Supplemental Fig. 2. Comparisons of the morphology of early roots and leaves of 'Wuqing' radish, dualuse radish and potherb mustard after one month of growth. (A) Continued development of 'Wuqing' radish leaves; square indicates the distribution of leaf trichomes. (B) Continued development of potherb mustard leaves; square indicates the distribution of leaf trichomes. (C) Continued development of dual-use radish leaves; square indicates the distribution of leaf trichomes. (D) Comparison of roots after one month of growth for 'Wuqing' radish (left), dual-use radish (middle), and potherb mustard (right). 
Supplemental Table. 1. Sequence of primers on SSR.

\begin{tabular}{|c|c|c|}
\hline & $5^{\prime} \rightarrow 3^{\prime}$ & Temperature $\left({ }^{\circ} \mathrm{C}\right)$ \\
\hline \multirow[t]{2}{*}{$\overline{\mathrm{P}-1}$} & CCCGCACCTTCTTCCTTCTCATTTC & 54 \\
\hline & TGTCGCCGGAGCTCTCTTTATTGTG & \\
\hline \multirow[t]{2}{*}{$\mathrm{P}-2$} & GCAGACAAGAAATTCTCGCCATGTC & 54 \\
\hline & GACATTGGCGAAAGTCTTGAACTGG & \\
\hline \multirow[t]{2}{*}{ P-3 } & CAAAGCGAGAAAGTGCAGTTGAGAG & 54 \\
\hline & TCCACGAAACTACTGCAGATTGAAA & \\
\hline \multirow[t]{2}{*}{ P-4 } & AGTCGAGATCTCGTTCGTGTCTCCC & 54 \\
\hline & TGAAGAAGGATTGAAGCTGTTGTTG & \\
\hline \multirow[t]{2}{*}{ P-5 } & GAGACGAGTGTTTTGTTGGCAGTTG & 54 \\
\hline & CGACGAGAACCAACACATAACAACC & \\
\hline \multirow[t]{2}{*}{ P-6 } & TGAGGTTAGACATGGCGCTGCTTGC & 54 \\
\hline & TTTGATCATTGTGGTCGCGAGTTCG & \\
\hline \multirow[t]{2}{*}{ P-7 } & CCATCTGTTGAGAGCTTCTTCTTC & 54 \\
\hline & AAGTTCATTTGCTCCGATGC & \\
\hline \multirow[t]{2}{*}{ P-8 } & СTCTTCCTTCTCGATGTTATTTCAG & 54 \\
\hline & CACGTGCCATTCCAATAAGC & \\
\hline \multirow[t]{2}{*}{ P-9 } & AATACTTTCTGAAGTTGTCCGCTAA & 54 \\
\hline & AACCTACGCAAGATGCTTCTACTT & \\
\hline \multirow[t]{2}{*}{ P-10 } & CAGAAGTGGAGGTAGTAAAACCAAA & 54 \\
\hline & ATCTTCCTCATTCTCATTCGCTAC & \\
\hline P-11 & AATTTTCAACGCCTTCATCCTGT & 54 \\
\hline & GGTGAATGCATCAGTCGACATAACT & \\
\hline $\mathrm{P}-12$ & CTGTTTCTGCTGTACCGAGTGGTAG & 54 \\
\hline & GATACATGGTGGGATAAGGTTGCT & \\
\hline $\mathrm{P}-13$ & САTCCTAATGTTGCTGAGAAAGAGG & 54 \\
\hline & TATATGAAACCGATGAAGCTCCTTT & \\
\hline P-14 & ACTCAACAACCGAACAAGAAAAACA & 54 \\
\hline & CGGTAGAGAACAGAGGAAGCCTAAG & \\
\hline P-15 & AACTTAACCGAAACCGAGATAGGTG & 54 \\
\hline & AATCTCGAAATTCATCGACTTCCTC & \\
\hline P-16 & GCATACCAGAGGACCAAA & 54 \\
\hline & GTTCCAAATCCCTAATGAC & \\
\hline P-17 & ATCCCATTCAAGTCCAGAAG & 54 \\
\hline & AGCAGAGGAACAAACACATAC & \\
\hline P-18 & GATTCTTGTGGCAGAGTTTC & 54 \\
\hline & СТCCTCACTGTTCTCCGT & \\
\hline P-19 & TGTATGGAACAACAACTCCTC & 54 \\
\hline & CTGCCACAACAATCACAAG & \\
\hline $\mathrm{P}-20$ & GATTCTTGTGGCAGAGTTTC & 54 \\
\hline & GAGTAGATGCTTTGGTTGGTC & \\
\hline $\mathrm{P}-21$ & GGATCAGTTATCTGCACCACAA & 54 \\
\hline & TCGGAATTGGATAAGAATTCAA & \\
\hline $\mathrm{P}-22$ & GACTTTCCCGATTTGCTTTTTCCAG & 54 \\
\hline & GGAGGGTTCGGGTCTTACAAGTTTG & \\
\hline $\mathrm{P}-23$ & GAATCAATGGTCCAGATTTCTTTTA & 54 \\
\hline & ATCTCTCCCTCTTGTCGTCATCT & \\
\hline P-24 & ATCTGATAACTGAGTGTCATTGTGC & 54 \\
\hline & CTCTGCTTCTTCATCGGAAAAAT & \\
\hline $\mathrm{P}-25$ & GAGTAGTACCAGGAAGGGTGACCTC & 54 \\
\hline & ACGCTTAACTGCGGAGTTCTGAT & \\
\hline P-26 & ACCCAAGTACGTGATGTGAACTTTG & 54 \\
\hline & GAAACAGAAGAGCAGGAGGAGGA & \\
\hline P-27 & CAAGTCGAAGAAGACATCTCCAAAC & 54 \\
\hline & TAAGCTTCTTCTCGAGCTTTTGGTT & \\
\hline $\mathrm{P}-28$ & TCATGGTCACCCGAAGTAATTAAAG & 54 \\
\hline & ACCGCAATCTCTCCGATAAACTCTA & \\
\hline P-29 & CTTCGGCATCGATTTCGT & 54 \\
\hline & TCTTCCTTGGGGAGAGGC & \\
\hline $\mathrm{P}-30$ & AAGGATGAACAAACGCCCAC & 54 \\
\hline & ACAACTTCAGAGTCTTCACG & \\
\hline $\mathrm{P}-31$ & GAATGGATTCGAGAAAAGGG & 54 \\
\hline & AGCACGTAGGTGAATGTATAG & \\
\hline P-32 & CGGCTCGTGGGTTTAATG & 54 \\
\hline & ACGAGTACAAAGACGAATG & \\
\hline P-33 & GATTAAGGAGAAGCTTCCAGG & 54 \\
\hline & GGAAAGCTGAAATCAACAAAGG & \\
\hline P-34 & GAGAGATAAAGGCTTAAAAGCG & 54 \\
\hline & GAAAGATAAAGGAGAGAGTCG & \\
\hline P-35 & GCTTCCCATGGCCATTCA & 54 \\
\hline & CGCCACTTTCTCCATGGT & \\
\hline P-36 & GGCAGAATCCCTCTTGCG & 54 \\
\hline & GGTACCAACAAAGATTCTC & \\
\hline P-37 & AGAGAGAAGGAGAGTTGTAG & 54 \\
\hline & TCCTAACATAGCGTGTACTG & \\
\hline
\end{tabular}

(Continued on next page) 
Supplemental Table. 1. (Continued) Sequence of primers on SSR.

\begin{tabular}{|c|c|c|}
\hline & $5^{\prime} \rightarrow 3^{\prime}$ & Temperature $\left({ }^{\circ} \mathrm{C}\right)$ \\
\hline \multirow[t]{2}{*}{$\begin{array}{l}\mathrm{P}-38 \\
\end{array}$} & GATTAAGGAGAAGCTTCCAGG & 54 \\
\hline & GGAAAGCTGAAATCAACAAAGG & \\
\hline \multirow[t]{2}{*}{ P-39 } & TCAATTGCACATTCTAGAATTCTAAG & 54 \\
\hline & CAATTCAATATGGTTATATATTAGAG & \\
\hline \multirow[t]{2}{*}{ P-40 } & GTGGTAGAAAGCAACGTGCGACTT & 54 \\
\hline & ACTTGAGTTACGAGAGTACGAATG & \\
\hline \multirow[t]{2}{*}{ MF-1 } & TCAATTGCACATTCTAGAATTCTAAG & 54 \\
\hline & CAATTCAATATGGTTATATATTAGAG & \\
\hline \multirow[t]{2}{*}{ MF-2 } & GGTTCCGTCGTTCCCATCGC & 54 \\
\hline & CATAATAATTAGATAAATCTGTTCC & \\
\hline \multirow[t]{2}{*}{ MF-3 } & AATGGTATGACTAGCTTATAAGG & 54 \\
\hline & CTTAACAATGAGATGAGGCAATC & \\
\hline \multirow[t]{2}{*}{ MF-4 } & CGGATCTATTATGACATATCC & 54 \\
\hline & GAAATATGAATACACTAGATTAGG & \\
\hline \multirow[t]{2}{*}{ MF-5 } & CCTGGCGGTATCAAGATGCCACT & 54 \\
\hline & GCCATAATGGTACAGAACTAT & \\
\hline \multirow[t]{2}{*}{ MF-6 } & GAAGGAATAGTCGTTTTCAAG & 54 \\
\hline & CATAAATAGAGTTCCATTTCGG & \\
\hline \multirow[t]{2}{*}{ MF-7 } & CGGCAGGAGTCATTGGTTCAAA & 54 \\
\hline & GATTTTGTAACTAGCTGACG & \\
\hline \multirow[t]{2}{*}{ MF-8 } & CTTATATTCATAAGCGAAGAAC & 54 \\
\hline & AATAACAATAGATGAATAGTCA & \\
\hline \multirow[t]{2}{*}{ MF-9 } & GGGCCGTTATGCTCATTACG & 54 \\
\hline & TCCTATTCATGGGGATTCCG & \\
\hline \multirow[t]{2}{*}{ MF-10 } & GTGGTAGAAAGCAACGTGCGACTT & 54 \\
\hline & ACTTGAGTTACGAGAGTACGAATG & \\
\hline
\end{tabular}

